\title{
Voltage Source Inverters Control using PWM/SVPWM For Adjustable Speed Drive Applications
}

\author{
Ghadeer Soud Al Shayaa, Hisham Mohamed Tawfik
}

\begin{abstract}
Pulse Width Modulation variable speed drives are ncreasingly applied in many new industrial applications that require superior performance. Recently, developments in power electronics and semiconductor technology have lead improvements in power electronic systems. Hence, different circuit configurations namely multilevel inverters have become popular and considerable interest by researcher are given on them. Variable voltage and frequency supply to a.c drives is invariably obtained from a three-phase voltage source inverter. A number of Pulse width modulation (PWM) schemes are used to obtain variable voltage and frequency supply. The most widely used PWM schemes for three-phase voltage source inverters are carrier-based sinusoidal $P W M$ and space vector PWM (SVPWM). There is an increasing trend of using space vector PWM (SVPWM) because of their easier digital realization and better $d c$ bus utilization. This research focuses on step by step development SVPWM implemented on an Induction motor. The model of a three-phase a voltage source inverter is discussed based on space vector theory. Simulation results are obtained using MATLAB/Simulink environmentfor effectiveness of the study.
\end{abstract}

\section{Introduction}

Three phase voltage-fed PWM inverters are recently showing growing popularity for multi-megawatt industrial drive applications. The main reasons for this popularity are easy sharing of large voltage between the series devices and the improvement of the harmonic quality at the output as compared to a two level inverter. In the lower end of power, GTO devices are being replaced by IGBTs because of their rapid evolution in voltage and current ratings and higher switching frequency. The Space Vector Pulse Width Modulation of a three level inverter provides the additional advantage of superior harmonic quality and larger under-modulation range that extends the modulation factor to $90.7 \%$ from the traditional value of $78.5 \%$ in Sinusoidal Pulse Width Modulation.

An adjustable speed drive (ASD) is a device used to provide continuous range process speed control (as compared to discrete speed control as in gearboxes or multi-speed motors). An ASD is capable of adjusting both speed and torque from an induction or synchronous motor. An electric ASD is an electrical system used to control motor speed. ASDs may be referred to by a variety of names, such as variable speed drives, adjustable frequency drives or variable frequency inverters. The latter two terms will only be used to refer to certain AC systems, as is often the practice, although some DC drives are also based on the principle of adjustable frequency.

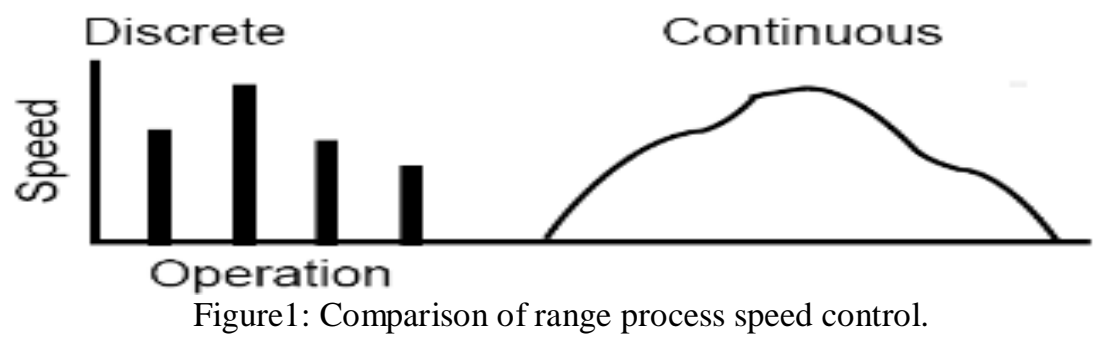

1.1 Latest Improvements

- Microprocessor-based controllers eliminate analog, potentiometer-based adjustments.

- Digital control capability.

- Built-in Power Factor correction.

- Radio Frequency Interference (RFI) filters.

- Short Circuit Protection (automatic shutdown).

- Advanced circuitry to detect motor rotor position by sampling power at terminals, ASD and motor circuitry combined to keep power waveforms sinusoidal, minimizing power losses.

- Motor Control Centers (MCC) coupled with the ASD using real-time monitors to trace motor- drive system performance.

- Higher starting torques at low speeds (up to $150 \%$ running torque) up to $500 \mathrm{HP}$, in voltage 
Source drives.

- Load-commutated Inverters coupled with synchronous motors. (Precise speed control in constant torque applications).

Adjustable speed drives are the most efficient (98\% at full load) types of drives. They are used to control the speeds of both AC and DC motors. They include variable frequency/voltage AC motor controllers for squirrel-cage motors, DC motor controllers for DC motors, eddy current clutches for AC motors (less efficient), wound-rotor motor controllers for wound-rotor AC motors (less efficient) and cycloconverters (less efficient).

Pulse Width Modulation variable speed drives are increasingly applied in many new industrial applications that require superior performance. Recently, developments in power electronics and semiconductor technology have lead improvements in power electronic systems. Hence, different circuit configurations namely multilevel inverters have beco me popular and considerable interests by researcher are given on them. Variable voltage and frequency supply to a.c drives is invariably obtained from a three-phase voltage source inverter. A number of Pulse width modulation (PWM) schemes are used to obtain variable voltage and frequency supply. The most widely used PWM schemes for three-phase voltage source inverters are carrier-based sinusoidal PWM and space vector PWM (SVPWM). There is an increasing trend of using space vector PWM (SVPWM) because of their easier digital realization and better dc bus utilization.

This project focuses on step by step development SVPWM implemented on an Induction motor. The model of a three-phase a voltage source inverter is discussed based on space vector theory. Simulation results are obtained using MATLAB/Simulink environment for effectiveness of the study.

\section{Voltage Source Inverters}

The main objective of static power converters is to produce an ac output waveform from a dc power supply. These are the types of waveforms required in adjustable speed drives (ASDs), uninterruptible power supplies (UPS), static var compensators, active filters, flexible ac transmission systems (FACTS), and voltage compensators, which are only a few applications. For sinusoidal ac outputs, the magnitude, frequency, and phase should be controllable.

According to the type of ac output waveform, these topologies can be considered as voltage source inverters (VSIs), where the independently controlled ac output is a voltage waveform. These structures are the most widely used because they naturally behave as voltage sources as required by many industrial applications, such as adjustable speed drives (ASDs), which are the most popular application of inverters. Similarly, these topologies can be found as current source inverters (CSIs), where the independently controlled ac output is a current waveform. These structures are still widely used in medium-voltage industrial applications, where high-quality voltage waveforms are required. Static power converters, specifically inverters, are constructed from power switches and the ac output waveforms are therefore made up of discrete values. This leads to the generation of waveforms that feature fast transitions rather than smooth ones.

For instance, the ac output voltage produced by the VSI of a standard ASD is a three- level waveform (Fig. 1c). Although this waveform is not sinusoidal as expected (Fig. 1b), its fundamental component behaves as such. This behavior should be ensured by a modulating technique that controls the amount of time and the sequence used to switch the power valves on and off. The modulating techniques most used are the carrierbased technique (e.g., sinusoidal pulse width modulation, SPWM), the space-vector (SV) technique, and the selective-harmonic- elimination (SHE) technique.

a)

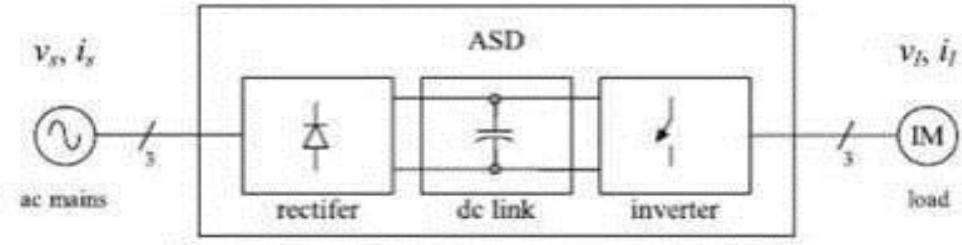

b)
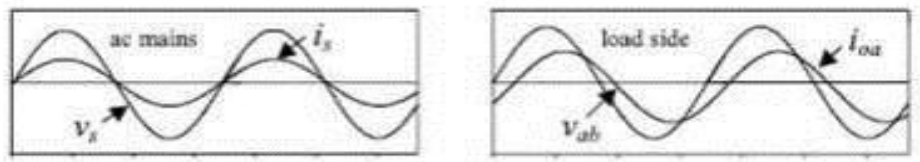

c)
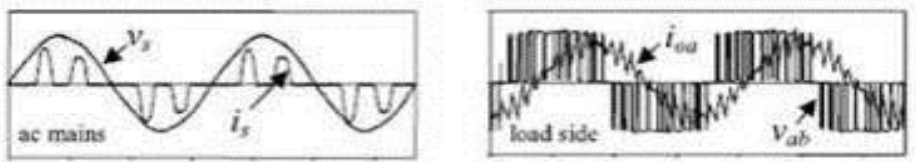

Fig. 1: The ac output voltage produced by the VSI of a standard ASD 
a) The electrical power conversion topology;

b) The ideal input (ac mains) and output (load) waveforms; and

c) The actual input (ac mains) and output (load) waveforms.

\subsection{Single-Phase Voltage Source Inverters}

Single-phase voltage source inverters (VSIs) can be found as half-bridge and full-bridge topologies. Although the power range they cover is the low one, they are widely used in power supplies, single-phase UPSs, and currently to form elaborate high-power static power topologies, such as for instance, the multicell configurations.

\subsubsection{Half-Bridge VSI}

Fig.2 shows the power topology of a half-bridge VSI, where two large capacitors are required to provide a neutral point $\mathrm{N}$, such that each capacitor maintains a constant voltage (Vi)/2. Because the current harmonics injected by the operation of the inverter are low-order harmonics, a set of large capacitors (C+ and $\mathrm{C}-$ ) is required. It is clear that both switches S+ and S- cannot be ON simultaneously because a short circuit across the dc link voltage source $\mathrm{Vi}$ would be produced. There are two defined (states 1 and 2) and one undefined (state 3) switch state as shown in Table

1. In order to avoid the short circuit across the dc bus and the undefined ac output voltage condition, the modulating technique should always ensure that at any instant either the top or the bottom switch of the inverter leg is on.

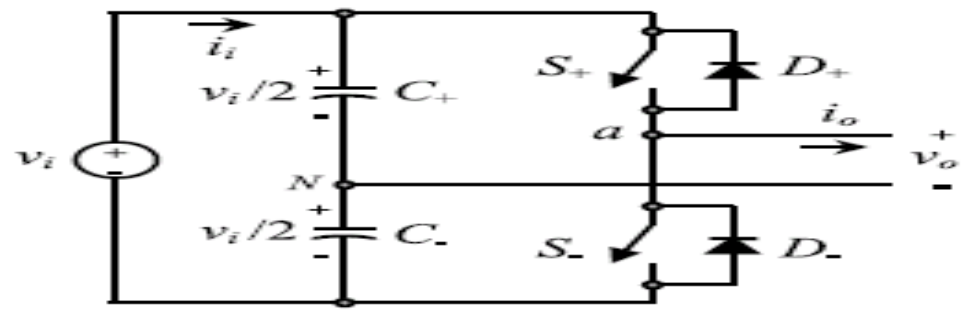

Fig. 2: Single-phase half-bridge VSI.

\begin{tabular}{llcr}
\hline State & State & $v$ & \multicolumn{2}{c}{$\begin{array}{l}\text { Components } \\
\text { Conducting }\end{array}$} \\
\hline+ is on and - is off & 1 & $v / 2$ & + if $>0$ \\
+ is on and + is off & 2 & $-v / 2$ & + if $<0$ \\
+ and - are all off & 3 & $-v / 2$ & - if $>0$ \\
& & $v / 2$ & + if $>0$ \\
\end{tabular}

Table 1: Switch states for a half-bridge single-phase VSI

\subsubsection{Full-Bridge VSI}

Fig. 3 shows the power topology of a full-bridge VSI. This inverter is similar to the half-bridge inverter; however, a second leg provides the neutral point to the load. As expected, both switches S1+ and S1(or S2+ and S2-) cannot be on simultaneously because a short circuit across the dc link voltage source Vi would be produced. There are four defined (states 1,2, 3, and 4) and one undefined (state 5) switch states as shown in Table 2. The undefined condition should be avoided so as to be always capable of defining the ac output voltage. It can be observed that the ac output voltage can take values up to the dc link value $\mathrm{Vi}$, which is twice that obtained with half-bridge VSI topologies. Several modulating techniques have been developed that are applicable to full- bridge VSIs. Among them are the PWM (bipolar and unipolar) techniques.

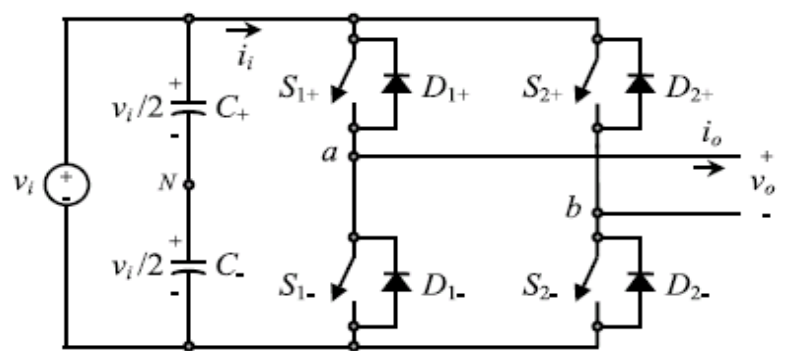

Fig. 3: Single-phase full-bridge VSI. 


\begin{tabular}{|c|c|c|c|c|c|c|c|c|}
\hline State & State & $v_{a}$ & $v_{b}$ & $v$ & Compon & ents & Ictir & \\
\hline${ }_{1+}$ and $2-$ are on and $1-$ and $2+$ are off & 1 & $v / 2$ & $-v / 2$ & $v$ & $1+$ and & $2-$ & $\begin{array}{l}\text { if } \\
\text { if }\end{array}$ & $\begin{array}{l}>0 \\
<0\end{array}$ \\
\hline $1-$ and $2+$ are on and $1+$ and $2-$ are off & 2 & $-v / 2$ & $v / 2$ & $-v$ & $\begin{array}{l}1-\text { and } \\
1-\text { and }\end{array}$ & $\begin{array}{cl}2+ \\
2+\end{array}$ & $\begin{array}{l}\text { if } \\
\text { if }\end{array}$ & $\begin{array}{l}>0 \\
<0\end{array}$ \\
\hline${ }_{1+}$ and $2+$ are on and $1-$ and $2-$ are off & 3 & $v / 2$ & $v / 2$ & 0 & $\begin{array}{l}1+\text { and } \\
1+\text { and }\end{array}$ & $\begin{array}{c}2+ \\
2+\end{array}$ & $\begin{array}{l}\text { if } \\
\text { if }\end{array}$ & $\begin{array}{l}>0 \\
<0\end{array}$ \\
\hline $1-$ and $2-$ are on and $1+$ and $2+$ are off & 4 & $-v / 2$ & $-v / 2$ & 0 & $\begin{array}{l}1-\text { and } \\
1-\text { and }\end{array}$ & $2-$ & $\begin{array}{l}\text { if } \\
\text { if }\end{array}$ & $\begin{array}{l}>0 \\
<0\end{array}$ \\
\hline $1-, 2-, 1+$, and $2+$ are all off & 5 & $\begin{array}{r}-v / 2 \\
v / 2\end{array}$ & $\begin{array}{r}v / 2 \\
-v / 2\end{array}$ & $\begin{array}{r}-v \\
v\end{array}$ & $\begin{array}{l}1-\text { and } \\
1+\text { and }\end{array}$ & $\begin{array}{l}2+ \\
2-\end{array}$ & $\begin{array}{l}\text { if } \\
\text { if }\end{array}$ & $\begin{array}{l}>0 \\
<0\end{array}$ \\
\hline
\end{tabular}

Table 2: Switch states for a full-bridge single-phase VSI

\subsection{Three Phase Voltage Source Inverters}

Single-phase VSIs cover low-range power applications and three-phase VSIs cover the medium- to high-power applications. The main purpose of these topologies is to provide a three-phase voltage source, where the amplitude, phase, and frequency of the voltages should always be controllable. Although most of the applications require sinusoidal voltage waveforms (e.g., ASDs, UPSs, FACTS, VAR compensators), arbitrary voltages are also required in some emerging applications (e.g., active filters, voltage compensators).

The standard three-phase VSI topology is shown in Fig. 4 and the eight valid switch states are given in Table 3. As in single-phase VSIs, the switches of any leg of the inverter (S1 and S4, S3 and S6, or S5 and S2) cannot be switched on simultaneously because this would result in a short circuit across the dc link voltage supply. Similarly, in order to avoid undefined states in the VSI, and thus undefined ac output line voltages, the switches of any leg of the inverter cannot be switched off simultaneously as this will result in voltages that will depend upon the respective line current polarity. Of the eight valid states, two of them (7 and 8 in Table

3) produce zero ac line voltages. In this case, the ac line currents freewheel through either the upper or lower components. The remaining states (1 to 6 in Table 3 ) produce non-zero ac output voltages. In order to generate a given voltage waveform, the inverter moves from one state to another. Thus the resulting ac output line voltages consist of discrete values of voltages that are $\mathrm{Vi}, 0$, and $-\mathrm{Vi}$ for the topology shown in Fig. 4. The selection of the states in order to generate the given waveform is done by the modulating technique that should ensure the use of only the valid states.

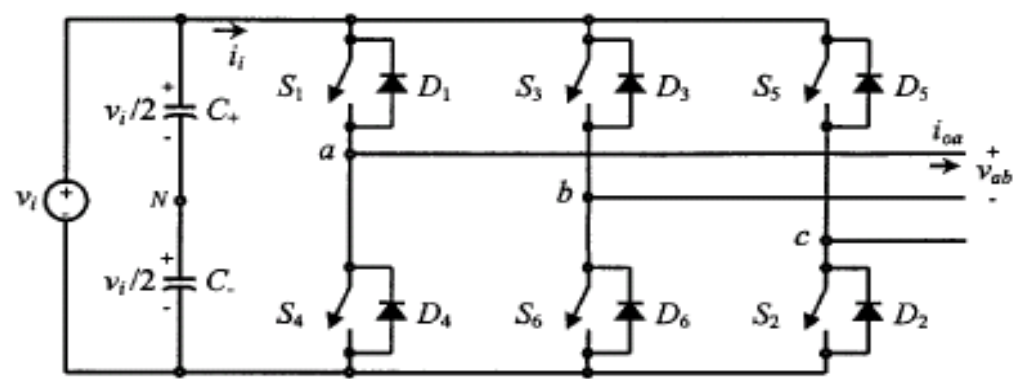

Fig. 4: Three-phase VSI topology.

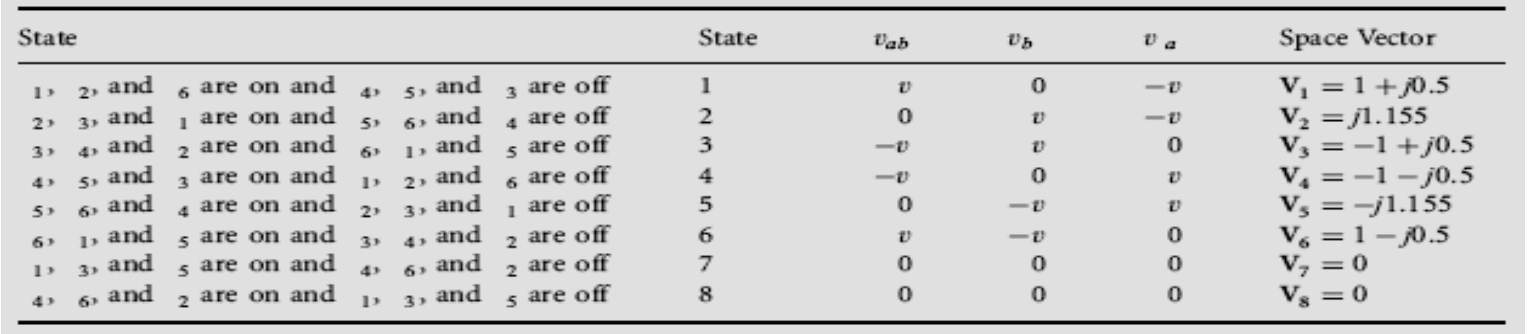

Table 3: Valid switch states for a three-phase VSI

\section{Pulse Width Modulation in Inverters}

Output voltage from an inverter can also be adjusted by exercising a control within the inverter itself. The most efficient method of doing this is by pulse-width modulation control used within an inverter.

In this method, a fixed dc input voltage is given to the inverter and a controlled ac output voltage is obtained by adjusting the on and off periods of the inverter components. This is the most popular method of controlling the output voltage and this method is termed as Pulse-Width Modulation (PWM) Control. 
The advantages possessed by PWM techniques are as under:

(i) The output voltage control with this method can be obtained without any additional components.

(ii) With the method, lower order harmonics can be eliminated or minimized along with its output voltage control. As higher order harmonics can be filtered easily, the filtering requirements are minimized.

The main disadvantage of this method is that SCRs are expensive as they must possess low turn- on and turnoff times.

PWM inverters are quite popular in industrial applications. PWM techniques are characterized by constant amplitude pulses. The width of these pulses is however modulated to obtain inverter output voltage control and to reduce its harmonic content.

The different PWM techniques are as under:
(a) Single-pulse modulation
(b) Multiple pulse modulations

(c) Sinusoidal pulse width modulation (Carrier based Pulse Width Modulation Technique)

Here we studied about Carrier based Pulse Width Modulation for open loop control of three phase induction motor drive.

\subsection{The Carrier-Based Pulse Width Modulation (PWM) Technique}

As mentioned earlier, it is desired that the ac output voltage $\boldsymbol{v}_{\boldsymbol{o}}=\boldsymbol{v}_{\boldsymbol{a}} \boldsymbol{N}$ follow a given waveform (e.g., sinusoidal) on a continuous basis by properly switching the power valves. The carrier- based PWM technique fulfils such a requirement as it defines the on and off states of the switches of one leg of a VSI by comparing a modulating signal $v_{c}$ (desired ac output voltage) and a triangular waveform $v_{\Delta}$ (carrier signal). In practice, when $\boldsymbol{v}_{\boldsymbol{c}}>\boldsymbol{v}_{\Delta} \boldsymbol{t h e}$ switch $\mathrm{S}+$ is on and the switch $\mathrm{S}$ - is off; similarly, when $\boldsymbol{v}_{\boldsymbol{c}}<\boldsymbol{v}_{\Delta}$ the switch $\mathrm{S}+$ is off and the switch S- is on.

A special case is when the modulating signal $v_{\boldsymbol{c}}$ is a sinusoidal at frequency $f \boldsymbol{c}$ and amplitude $\boldsymbol{v}^{\wedge} \boldsymbol{c}$, and the triangular signal $\boldsymbol{v}_{\Delta}$ is at frequency $f_{\Delta}$ and amplitude $\boldsymbol{v}^{\wedge} \Delta$. This is the sinusoidal PWM (SPWM) scheme. In this case, the modulation index $\boldsymbol{m}_{\boldsymbol{a}}$ (also known as the amplitude-modulation ratio) is defined as

$$
m_{a}=\frac{\hat{v}_{c}}{\hat{v}_{\Delta}}
$$

And the normalized carrier frequency $\boldsymbol{m} \boldsymbol{f}$ (also known as the frequency-modulation ratio) is

$$
m_{f}=\frac{f_{\Delta}}{f_{c}}
$$

Fig. 5(e) clearly shows that the ac output voltage $\boldsymbol{v}_{\boldsymbol{o}}=\boldsymbol{v} \boldsymbol{a N}$ is basically a sinusoidal waveform plus harmonics, which features: (a) the amplitude of the fundamental component of the ac output voltage $\boldsymbol{v}^{\wedge} \mathbf{0 1}$ satisfying the following expression:

$$
\hat{v}_{o 1}=\hat{v}_{a N 1}=\frac{v_{i}}{2} m_{a}
$$

(b) For odd values of the normalized carrier frequency $\boldsymbol{m}_{\boldsymbol{f}}$ the harmonics in the ac output voltage

Appear at normalized frequencies $\boldsymbol{f} \boldsymbol{h}$ centered around $\boldsymbol{m} \boldsymbol{f}$ and its multiples, specifically,

$$
h=\operatorname{lm}_{f} \pm k \quad l=1,2,3, \ldots
$$

Where $\mathrm{k}=2,4$, and $6 \ldots$ for $\mathrm{l}=1,3,5 \ldots$. ; and $\mathrm{k}=1,3,5 \ldots$ for $\mathrm{l}=2,4,6 \ldots$;

(c) The amplitude of the ac output voltage harmonics is a function of the modulation index $\boldsymbol{m}_{\boldsymbol{a}}$

and is independent of the normalized carrier frequency $\boldsymbol{m}_{\boldsymbol{f}}$ for $\boldsymbol{m}_{\boldsymbol{f}}>9$;

(d) The harmonics in the de link current (due to the modulation) appear at normalized frequencies $\boldsymbol{f}_{\boldsymbol{p}}$ centered around the normalized carrier frequency $\boldsymbol{m} \boldsymbol{f}$ and its multiples, specifically,

$$
p=l m_{f} \pm k \pm 1 \quad l=1,2, \ldots
$$

Where $\mathrm{k}=2,4,6 \ldots$ for $1=1,3,5 \ldots \ldots$; and $\mathrm{k}=1,3,5 \ldots$ for $\mathrm{l}=2,4,6 \ldots$;

Additional important issues are: 
(a) For small values of $\boldsymbol{m}_{\boldsymbol{f}}\left(\boldsymbol{m}_{\boldsymbol{f}}<21\right)$, the carrier signal $\boldsymbol{v}_{\Delta}$ and the modulating signal $\boldsymbol{v}_{\boldsymbol{c}}$ should be synchronized to each other ( $\boldsymbol{m} \boldsymbol{f}$ integer), which is required to hold the previous features; if this is not the case, sub harmonics will be present in the ac output voltage;

(b) For large values of $\boldsymbol{m} \boldsymbol{f}(\boldsymbol{m} \boldsymbol{f}>21)$, the sub harmonics are negligible if an asynchronous PWM technique is used, however, due to potential very low-order sub harmonics, its use should be avoided; finally

(c) In the over modulation region $\left(\boldsymbol{m}_{\boldsymbol{a}}>1\right)$ some intersections between the carrier and the modulating signal are missed, which leads to the generation of low-order harmonics but a higher fundamental ac output voltage is obtained; unfortunately, the linearity between $\boldsymbol{m}_{\boldsymbol{a}}$ and $\boldsymbol{v}^{\wedge} \mathbf{0 1}$ achieved in the linear region Eq. (3) does not hold in the over modulation region, moreover, a saturation effect can be observed (Fig. 6).
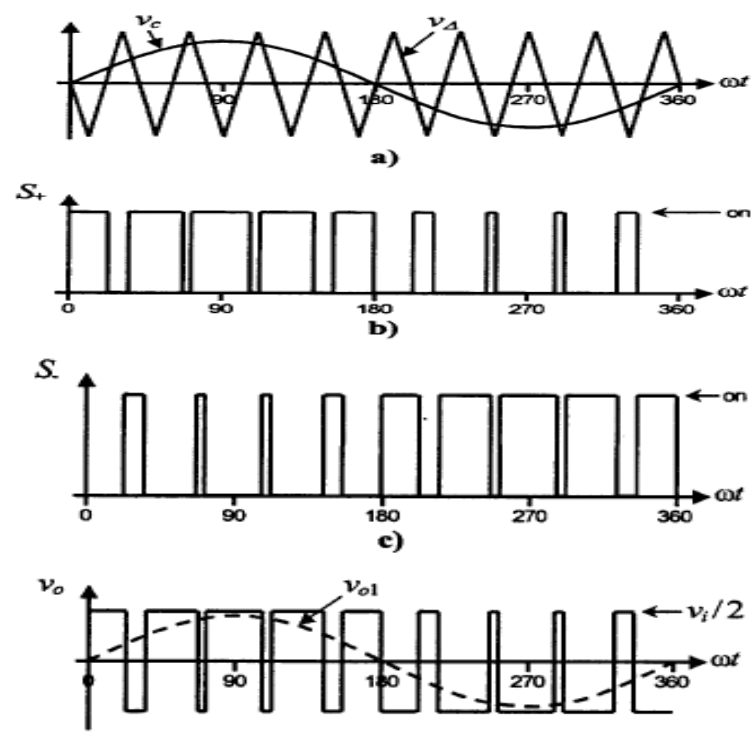

d)

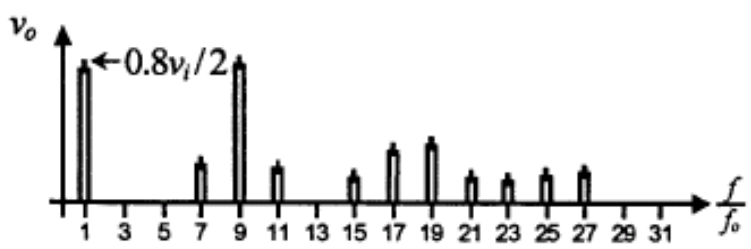

e)

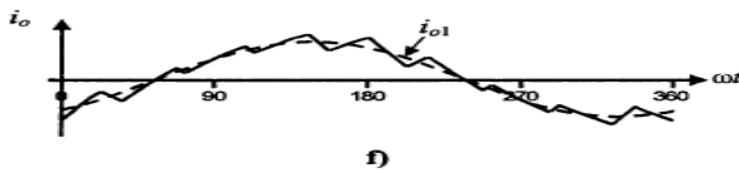

$i_{i}$

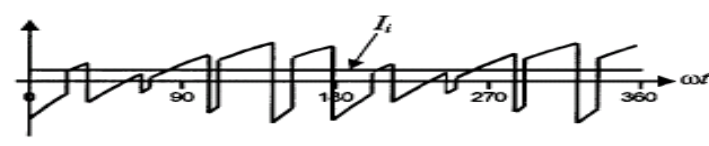

g)

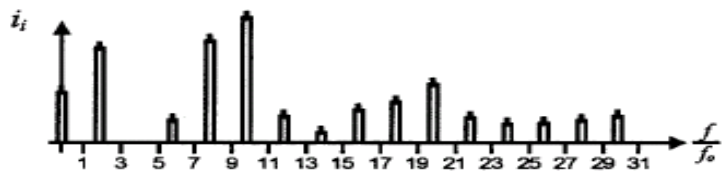

h)
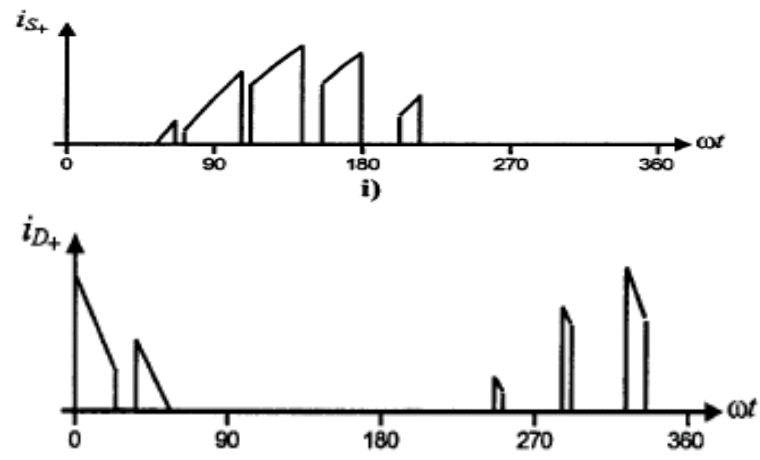

j)

Fig. 5: The half-bridge VSI. Ideal waveforms for the SPWM $\left(m_{a}=0.8, \mathrm{mf}=9\right)$ :

(a) carrier and modulating signals; (b) switch S+ state; (c) switch S- state; (d) ac output voltage; (e) ac output voltage spectrum; (f) ac output current; (g) dc current; (h) dc current spectrum; (i)

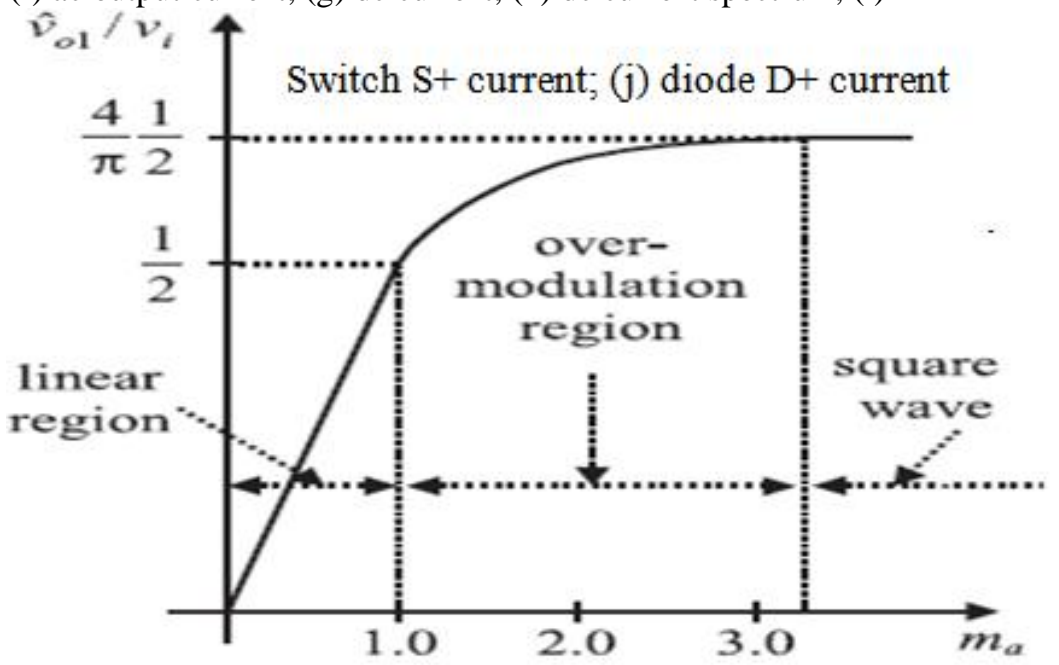

Fig. 6: Fundamental ac component of the voltage in a output Half-bridge VSI SPWM modulated 


\subsubsection{SPWM for Full Bridge VSI}

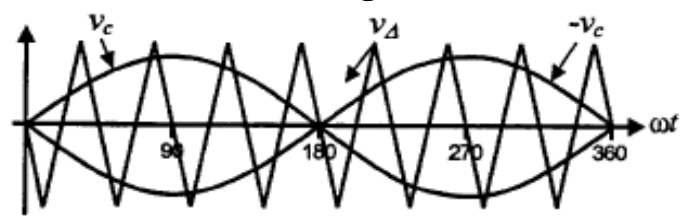

a)

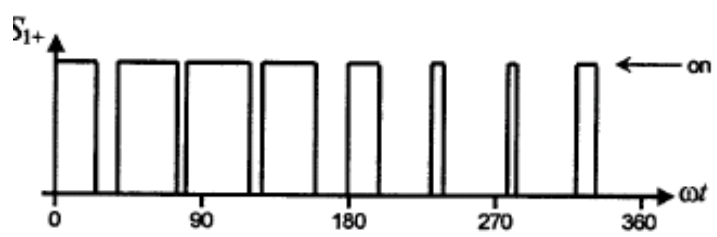

b)

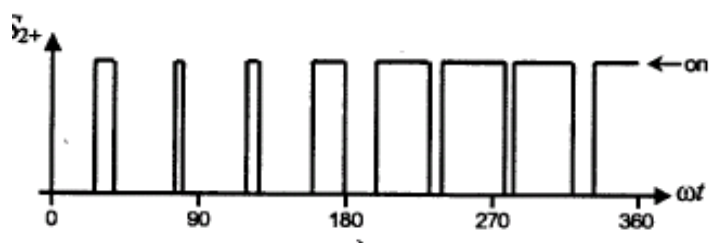

c)

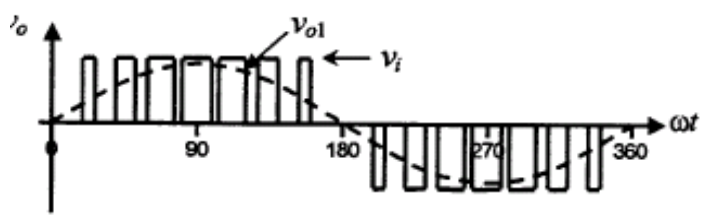

d)

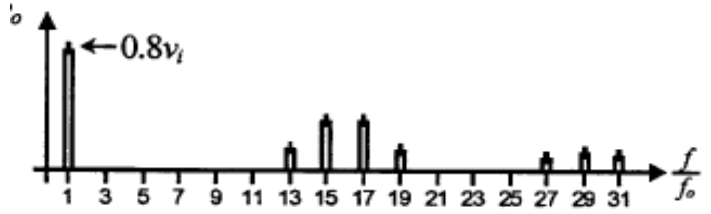

e)

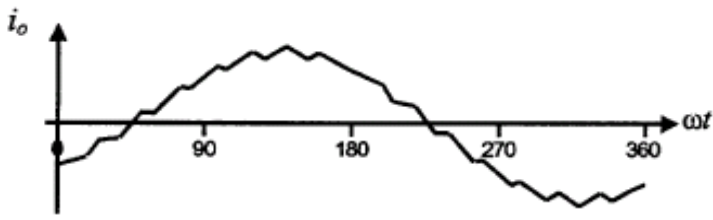

f)

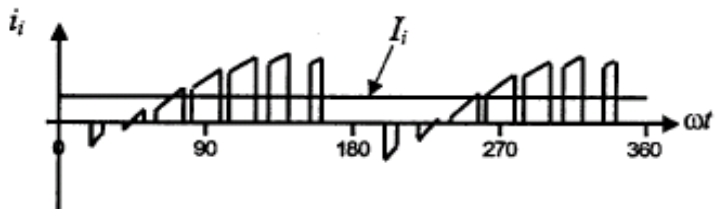

g)

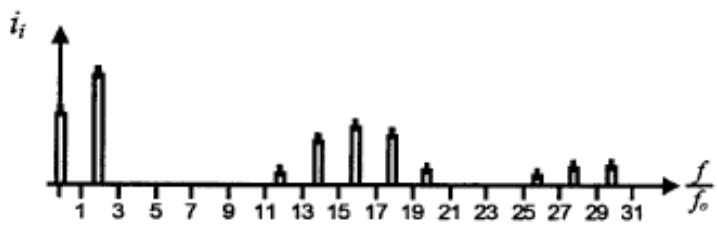

h)

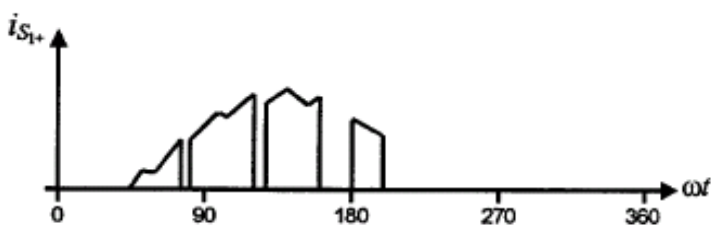

i)

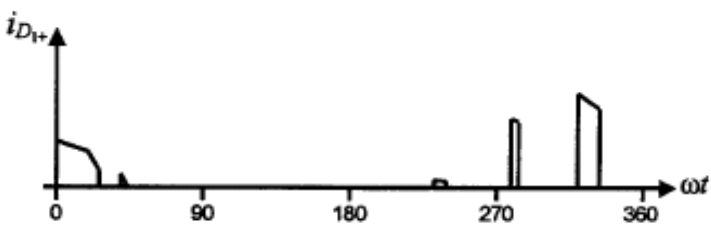

Fig. 7: The full-bridge VSI. Ideal waveforms for SPWM $\left(m_{a}=0.8, m_{f}=0.8\right)$ :

(a) carrier and modulating signals; (b) switch $\mathrm{S}_{1}+$ state; (c) switch $\mathrm{S}_{2}+$ state; (d) ac output voltage; (e) ac output voltage spectrum; (f) ac output current; (g) dc current; (h) dc current spectrum; (i) switch $\mathrm{S} 1+$ current; (j) diode $\mathrm{D} 1+$ current.

\subsubsection{SPWM for Three Phases VSI}

This is an extension of the one introduced for single-phase VSIs. In this case and in order to produce $120^{\circ}$ out-of-phase load voltages, three modulating signals that are $120^{\circ}$ out of phase are used. Fig. 8 shows the ideal waveforms of threephase VSI SPWM. In order to use a single

Carrier signal and preserve the features of the PWM technique, the normalized carrier frequency mf should be an odd multiple of 3. Thus, all phase voltages ( $\mathrm{vaN}, \mathrm{vbN}$, and $\mathrm{vcN}$ ) are identical but $120^{\circ}$ out of phase without even harmonics; moreover, harmonics at frequencies a multiple of 3 are identical in amplitude and phase in all phases. For instance, if the ninth harmonic in phase aN

$$
v_{a N 9}(t)=\hat{v}_{9} \sin (9 \omega t)
$$

The ninth harmonic in phase $\boldsymbol{b} \boldsymbol{N}$ will be

$$
\begin{aligned}
v_{b N 9}(t) & =\hat{v}_{9} \sin \left(9\left(\omega t-120^{\circ}\right)\right) \\
& =\hat{v}_{9} \sin \left(9 \omega t-1080^{\circ}\right) \\
& =\hat{v}_{9} \sin (9 \omega t)
\end{aligned}
$$


Thus, the ac output line voltage $\boldsymbol{v} \boldsymbol{a} \boldsymbol{b}=\boldsymbol{v} \boldsymbol{a} \boldsymbol{N}-\boldsymbol{v} \boldsymbol{b} \boldsymbol{N}$ will not contain the ninth harmonic. Therefore, for odd multiple of 3 values of the normalized carrier frequency $\boldsymbol{m} \boldsymbol{f}$, the harmonics in the ac output

Voltage appear at normalized frequencies $\boldsymbol{f} \boldsymbol{h}$ centered around $\boldsymbol{m} \boldsymbol{f}$ and its multiples, specifically, at

$$
h=l m_{f} \pm k \quad l=1,2, \ldots
$$

Where $1=1,3,5 \ldots \ldots \ldots$ for $\mathrm{k}=2,4,6$; and $1=2,4,6 \ldots$ for $\mathrm{k}=1,5,7 \ldots$; such that $\boldsymbol{h}$ is not a multiple of 3 . Therefore, the harmonics will be at $\boldsymbol{m} \boldsymbol{f} \pm 2, \mathrm{mf} \pm 4 \ldots 2 \mathrm{mf} \pm 1,2 \mathrm{mf} \pm 5 \ldots, 3 \mathrm{mf} \pm$

$2,3 \mathrm{mf} \pm 4$. ., $4 \mathrm{mf} \pm 1,4 \mathrm{mf} \pm 5 \ldots$

For nearly sinusoidal ac load current, the harmonics in the dc link current are at frequencies given by

$$
h=l m_{f} \pm k \pm 1 \quad l=1,2, \ldots
$$

Where $1=0,2,4 \ldots$ for $\mathrm{k}=1,5,7 \ldots$ and $1=1,3,5 \ldots$ for $\mathrm{k}=2,4,6 \ldots$ Such that

$\boldsymbol{h}=\boldsymbol{l} * \boldsymbol{m} \boldsymbol{f} \pm \boldsymbol{k}$ is positive and not a multiple of 3 . For instance, Fig. $7 \mathrm{~h}$ shows the sixth harmonic $(\mathrm{h}=6)$, which is due to

$h=(1 * 9)-2-1=6$.

The identical conclusions can be drawn for the operation at small and large values of $\boldsymbol{m} \boldsymbol{f}$ as for the singlephase configurations. However, because the maximum amplitude of the fundamental phase voltage in the linear region $\left(\boldsymbol{m}_{\boldsymbol{a}}<=1\right)$ is $\boldsymbol{v} \boldsymbol{i} / \mathbf{2}$, the maximum amplitude of the fundamental ac output line voltage is $\boldsymbol{v}^{\wedge} \boldsymbol{a b} \boldsymbol{1}=$ $\left(\sqrt{ } 3 v_{i}\right) / 2$.

Therefore, one can write,

$$
\hat{v}_{a b 1}=m_{a} \sqrt{3} \frac{v_{i}}{2}, \quad 0<m_{a} \leq 1
$$

To further increase the amplitude of the load voltage, the amplitude of the modulating signal $\boldsymbol{v}^{\wedge} \boldsymbol{c}$ can be made higher than the amplitude of the carrier signal $v^{\wedge} \Delta$, which leads to over modulation. The relationship between the amplitude of the fundamental ac output line voltage and the dc link voltage becomes nonlinear as in singlephase VSIs. Thus, in the over modulation region, the line voltages range in

$$
\sqrt{3} \frac{v_{i}}{2}<\hat{v}_{a b 1}=\hat{v}_{b c 1}=\hat{v}_{c a 1}<\frac{4}{\pi} \sqrt{3} \frac{v_{i}}{2}
$$

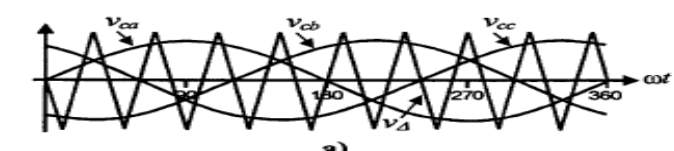

$S_{1}$

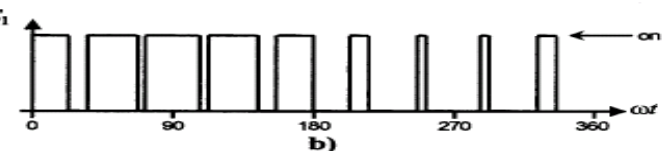

$S_{3}$
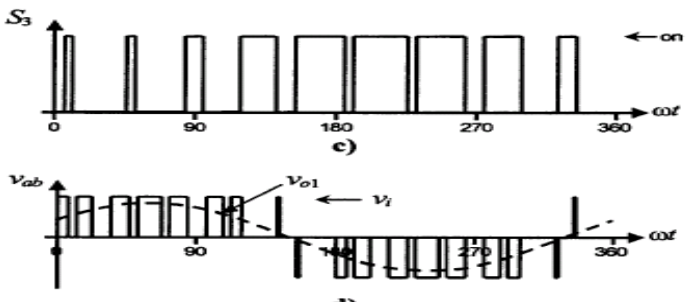

d)

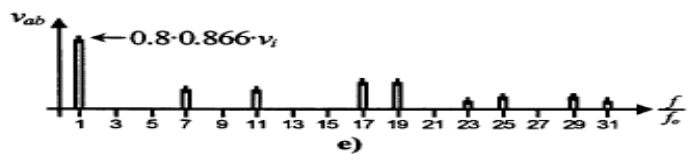

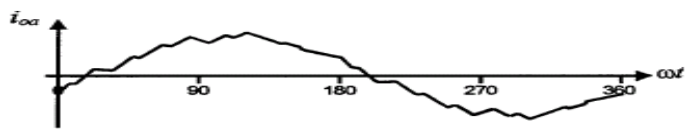

の

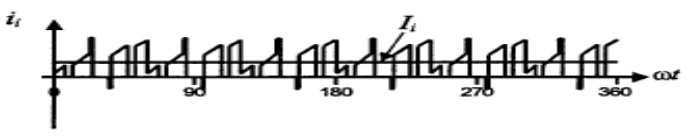

$i_{i}$
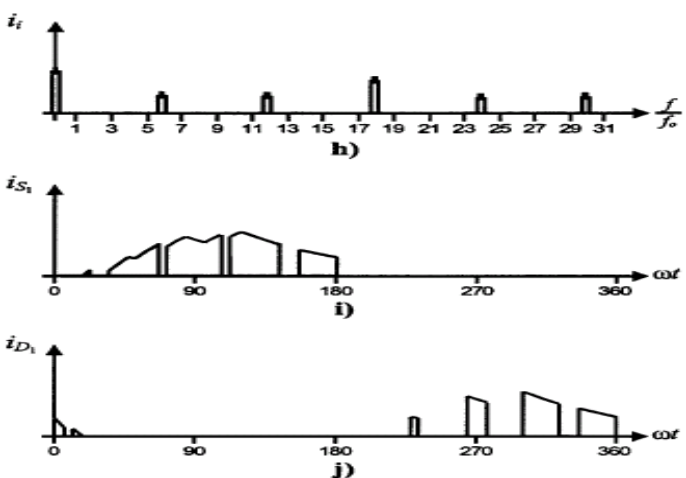

Fig. 8: The three-phase VSI. Ideal waveforms for the SPWM $\left(m_{a}=0.8, m_{f}=0.9\right)$ :

(a) carrier and modulating signals; (b) switch $\mathrm{S}_{1}$ state; (c)switch $\mathrm{S}_{3}$ state; (d) ac output voltage; (e) ac output voltage spectrum; (f) ac output current; (g) dc current; (h) dc current spectrum; (i) switch $\mathrm{S}_{1}$ current; (j) diode D1 current. 


\section{Space Vector Pulse Width Modulation for 3-phase VSI}

The topology of a three-leg voltage source inverter is shown in Fig. 9. Because of the constraint that the input lines must never be shorted and the output current must always be continuous a voltage source inverter can assume only eight distinct topologies. These topologies are shown on Fig. 10. Six out of these eight topologies produce a nonzero output voltage and are known as non-zero switching states and the remaining two topologies produce zero output voltage and are known as zero switching states

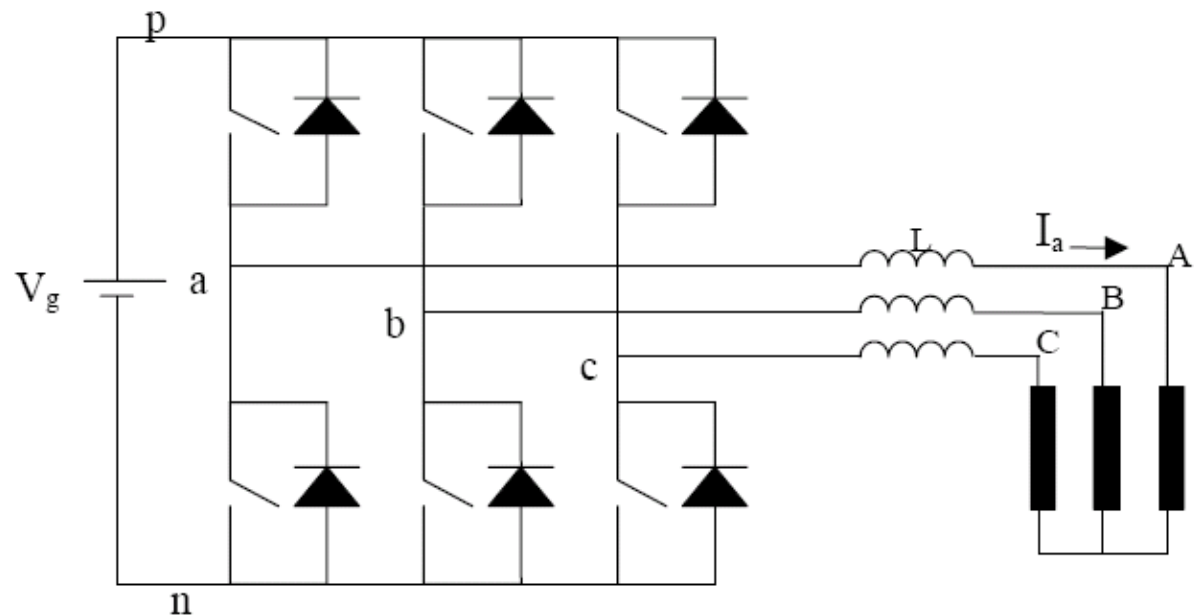

Fig. 9: Topology of a three-leg voltage source inverter
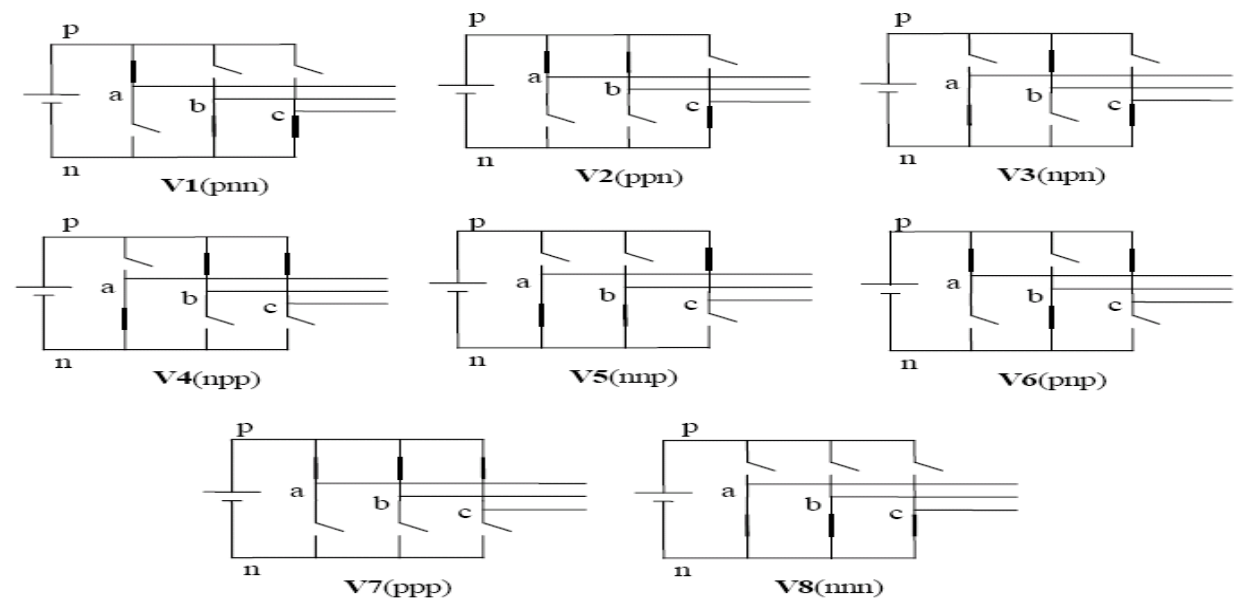

Fig. 10: Eight switching state topologies of a voltage source inverter.

\subsection{Voltage Space Vectors}

Space vector modulation (SVM) for three-leg VSI is based on the representation of the three phase quantities as vectors in a two-dimensional plane. This is illustrated here for the sake of completeness. Considering topology 1 of Fig. 10, which is repeated in Fig. 11(a) wex s\&e that the line voltages $\boldsymbol{V a b}, \boldsymbol{V b} \boldsymbol{c}$, and $\boldsymbol{V c a}$ are given by

$$
\begin{aligned}
& V_{a b}=V_{g} \\
& V_{b c}=0 \\
& V_{c a}=-V_{g}
\end{aligned}
$$

This can be represented in the, planexas shown in Fig. 11(b), where voltages $V a b, V b c$, and $V c a$ are three line voltage vectors displaced 120 in space. The effective voltage vector generated by this topology is represented as $\mathbf{V} \mathbf{1}$ (pnn) in Fig. 11(b). Here the notation ,pnn" refers to the 
Three legs/phases a, b, c being either connected to the positive dc rail (p) or to the negative dc rail

(n). Thus ,pnn" corresponds to ,phase a" being connected to the positive dc rail and phases $\mathrm{b}$ and $\mathrm{c}$ being connected to the negative dc rail.

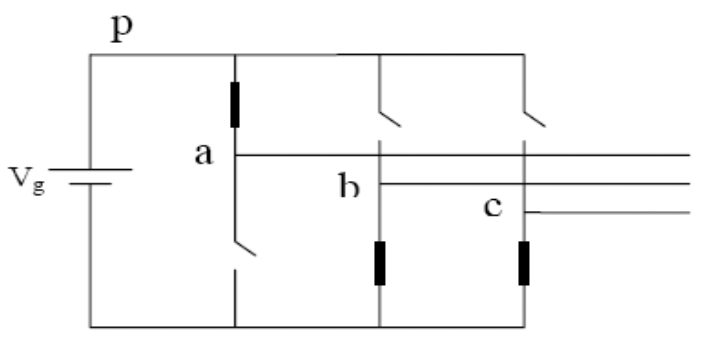

n

Fig. 11(a): Topology 1-V1 (pnn) of a voltage source inverter.

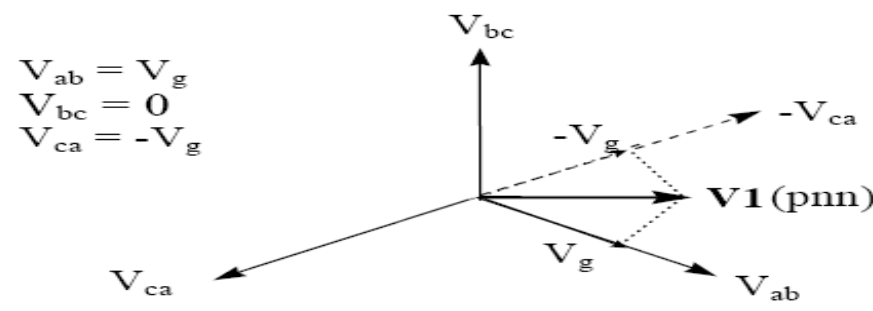

Fig. 11(b): Representation of topology 1 in the plane.

Proceeding on similar lines the six non-zero voltage vectors (V1 - V6) can be shown to assume the positions shown in Fig.12. The tips of these vectors form a regular hexagon (dotted line in Fig. 12). We define the area enclosed by two adjacent vectors, within the hexagon, as a sector.Thus there are six sectors numbered 1 - 6 in Fig. 12.

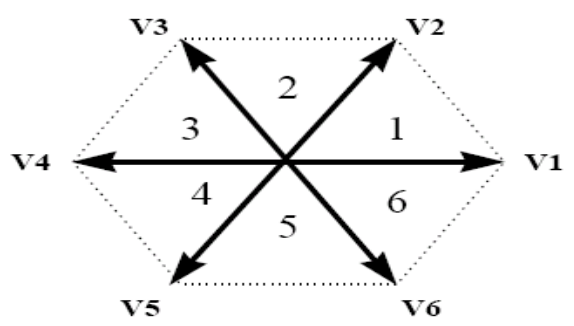

Fig. 12: Non-zero voltage vectors in the plane

Considering the last two topologies of Fig. 10 which are repeated in Fig. 13(a) for the sake of convenience we see that the output line voltages generated by this topology are given by

$$
\begin{aligned}
& V_{a b}=0 \\
& V_{b c}=0 \\
& V_{c a}=0
\end{aligned}
$$

These are represented as vectors which have zero magnitude and hence are referred to as zero - switching state vectors or zero voltage vectors. They assume the position at origin in the, plane as shown in Fig. 13(b). The vectors V1-V8 are called the switching state vectors (SSVs).

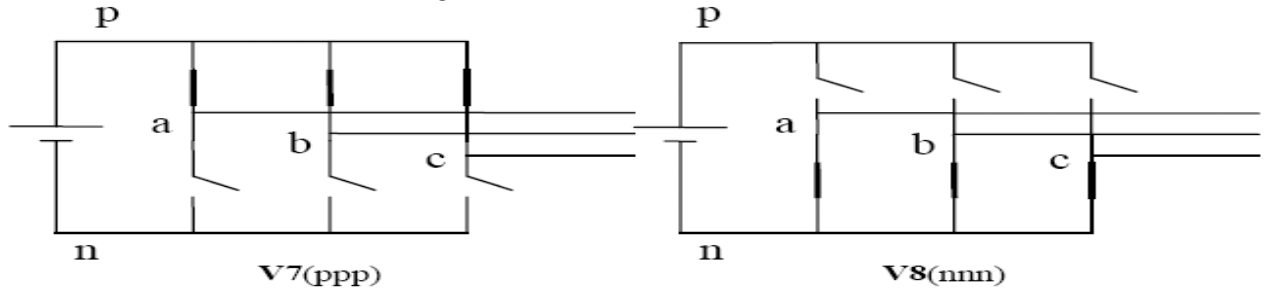

Fig 13(a): Zero output voltage topologies. 


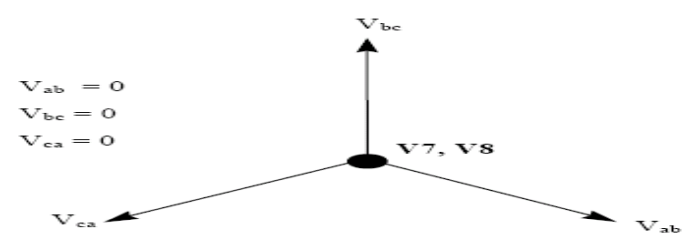

Fig. 13(b): Representation of the zero voltage vectors in the plane

\subsection{Space Vector Modulation}

The desired three phase voltages at the output of the inverter could be represented by an equivalent vector $\mathbf{V}$ rotating in the counter clock wise direction as shown in Fig. 14(a). The Magnitude of this vector is related to the magnitude of the output voltage (Fig. 14(b)) and the time this vector takes to complete one revolution is the same as the fundamental time period of the output voltage.

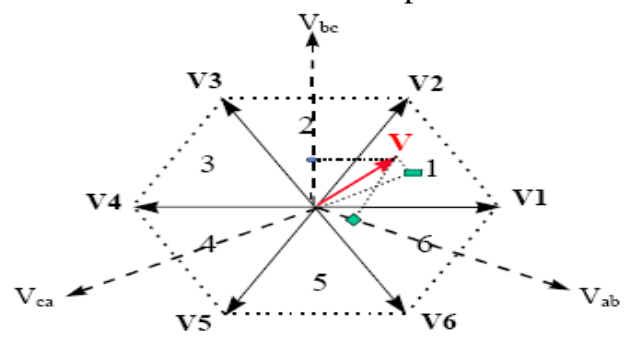

Fig. 14(a): Output voltage vector in the plane.

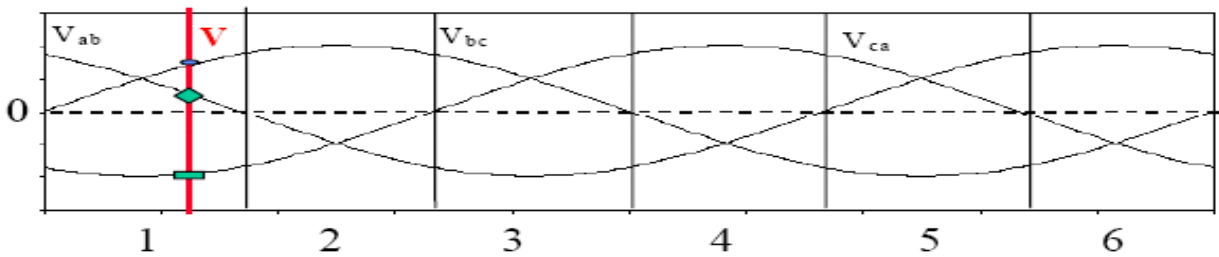

Fig. 14(b): Output line voltages in time domain.

Let us consider the situation when the desired line-to-line output voltage vector $\mathbf{V}$ is in sector 1 as shown in Fig. 15. This vector could be synthesized by the pulse-width modulation (PWM) of the two adjacent SSV"s V1 (pnn) and V2 (ppn), the duty cycle of each being d1 and d2, Respectively, and the zero vectors (V7 (nnn) / V8 (ppp)) of duty cycle do:

$$
\begin{gathered}
d_{1} \boldsymbol{V}_{1}+d_{2} \boldsymbol{V}_{2}=\boldsymbol{V}=m V_{g} e^{j \grave{e}} \\
d_{1}+d_{2}+d_{0}=1
\end{gathered}
$$

Where, $0 \lesssim \quad 6.866$, is the modulation index. This would correspond to a maximum line-to-line voltage of $1.0 \mathrm{Vg}$, which is $15 \%$ more than conventional sinusoidal PWM as shown.

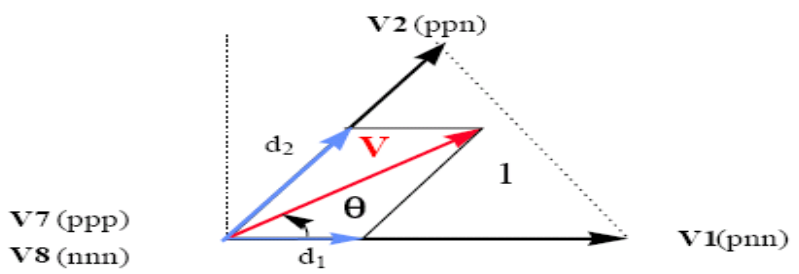

Fig. 15: Synthesis of the required output voltage vector in sector 1.

All SVM schemes and most of the other PWM algorithms use Eqns. (14) and (15) for the output voltage synthesis. The modulation algorithms that use non-adjacent SSV"s have been shown to produce higher THD and/or switching losses and are not analyzed here, although some of them,

e.g. hysteresis, can be very simple to implement and can provide faster transient response. The duty cycles $\mathrm{d} 1$, d2, and d0, are uniquely determined from Fig. 2.7, and Eqns. (14) and (15), the only difference between PWM schemes that use adjacent vectors is the choice of the zero vector(s) and the sequence in which the vectors are applied within the switching cycle. 
The degrees of freedom we have in the choice of a given modulation algorithm is:

1) The choice of the zero vector; whether we would like to use V7(ppp) or V8(nnn) or both,

2) Sequencing of the vectors

3) Splitting of the duty cycles of the vectors without introducing additional commutations.

\subsection{Implementing SVPWM}

The SVPWM can be implemented by using wither sector selection algorithm or by using a carrier based space vector algorithm.

The types of SVPWM implementations are:-

a) Sector selection based space vector modulation

b) Reduced switching Space vector modulation

c) Carrier based space vector modulation

d) Reduced switching carrier based space vector modulation.

\subsubsection{Sector selection based SVPWM:}

The figure below above provides an idea of the sector selection based space vector modulation. We have implanted the same using the Simulink blocks and s-functions algorithms wherever needed.

\subsubsection{Reduced switching SVPWM:}

The switching of the IGBTs can be reduced by $33 \%$ by choosing to use one of the zero vectors during each sector. The implementation is shown in the figure below.

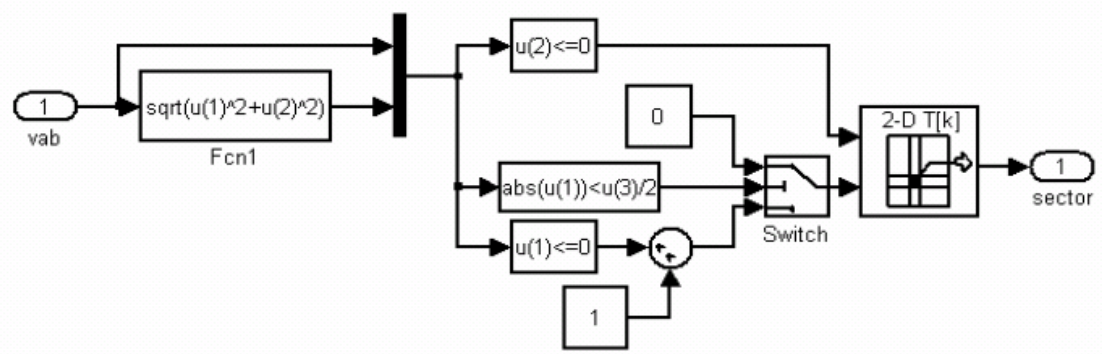

Fig.16: a Sector selection algorithm

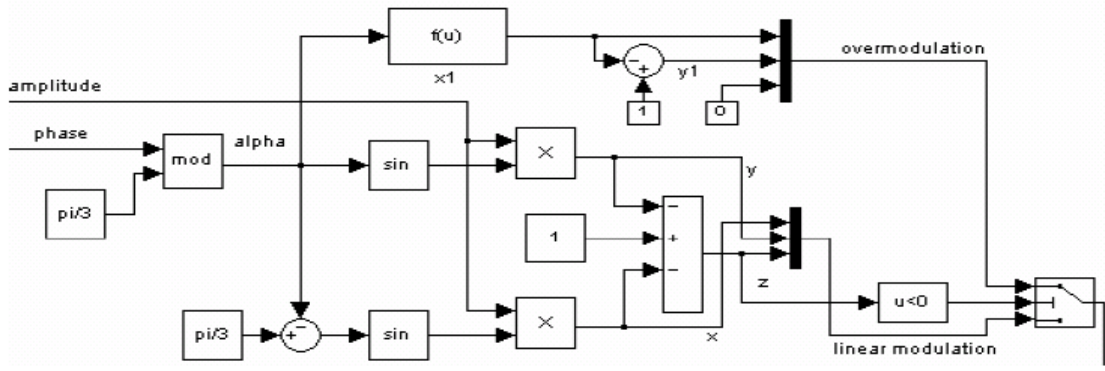

Fig. 17: Deriving the weights of the adjacent non-zero basic vector

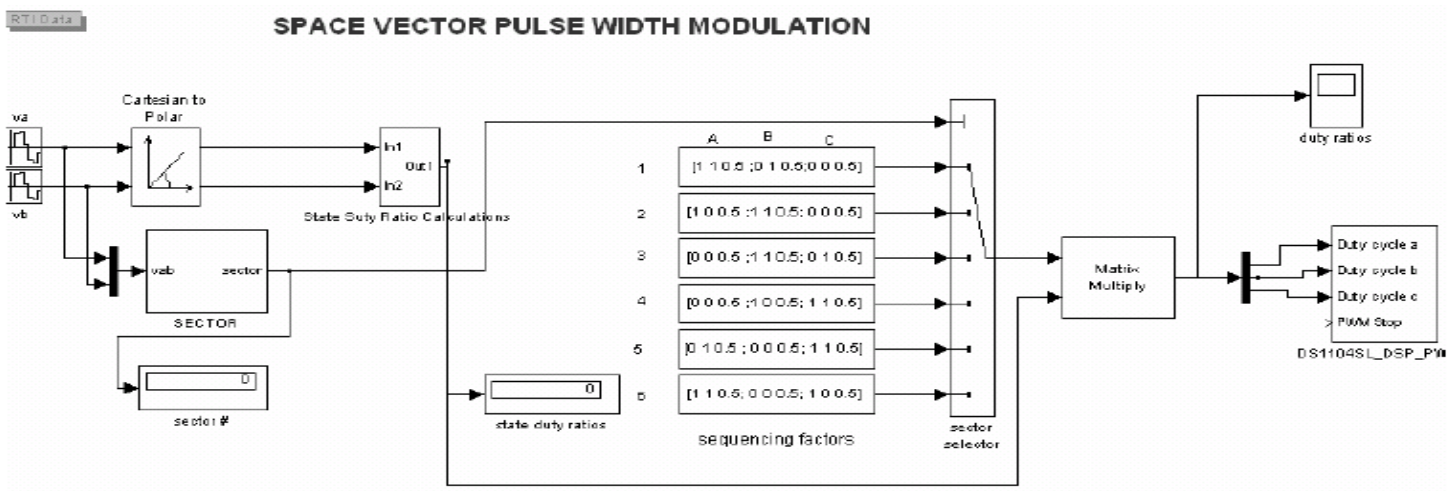

Fig. 18: Space Vector Modulation Simi link model 


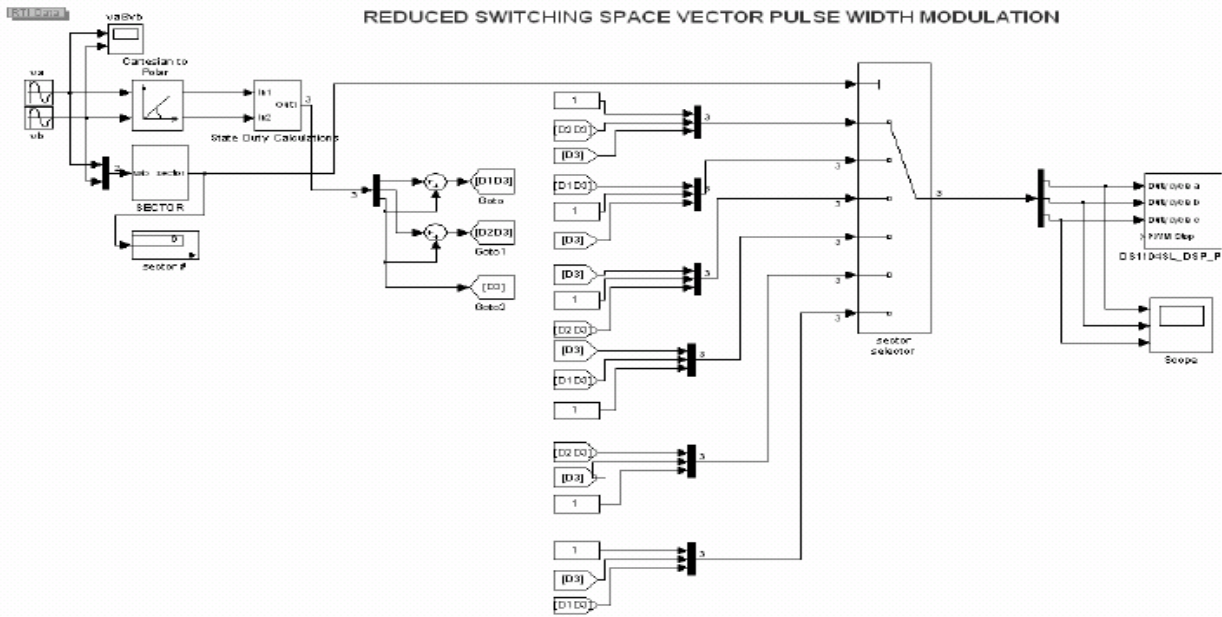

Figure 19: Reduced switching Space vector Modulation

\subsubsection{Carrier Based SVPWM:}

Carrier based SVPWM allow fast and efficient implementation of SVPWM without sector determination. The technique is based on the duty ratio profiles that SVPWM exhibits (as shown in Fig. 15 and 16). By comparing the duty ratio profile with a higher frequency triangular carrier the pulses can be generated, based on the same arguments as the sinusoidal pulse width modulation.

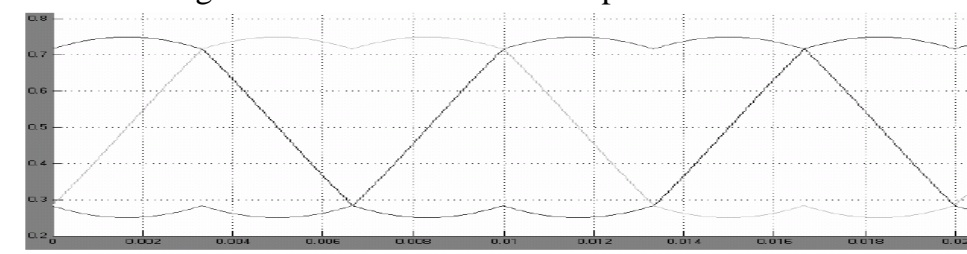

Fig. 20: Duty Ratio Profile with standard SVPWM

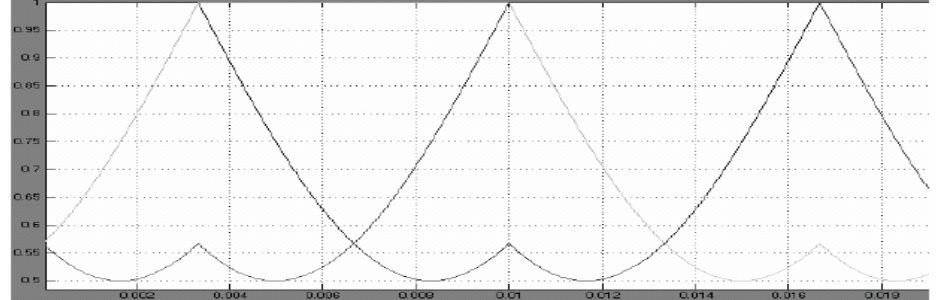

Fig. 21: Duty Ratio Profile with reduced switching SVPWM

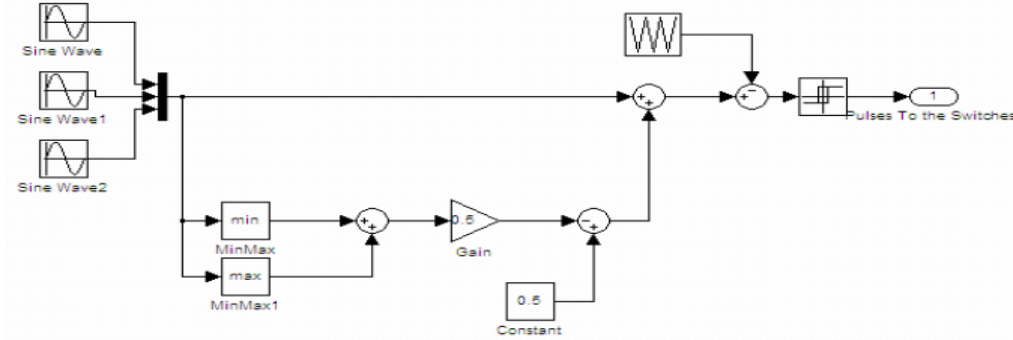

Fig. 22: Carrier Based Space Vector Modulation based on common mode voltage addition

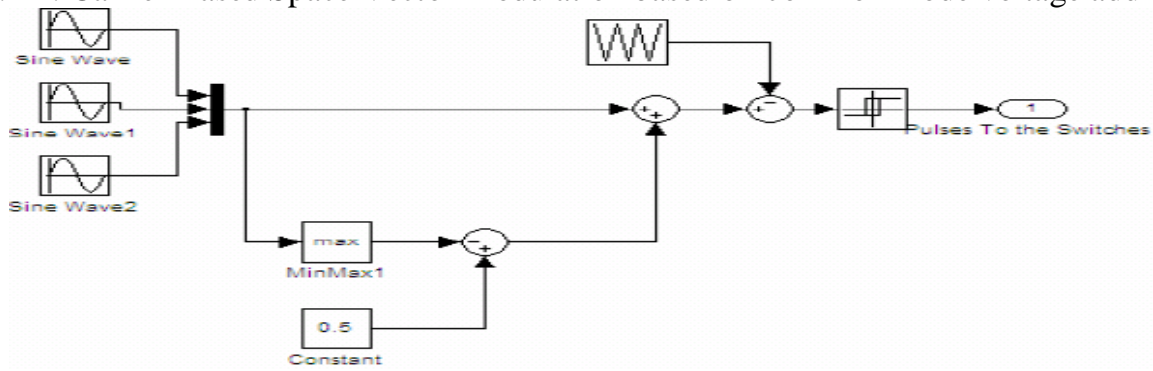

Fig. 23: Reduced Switching Carrier Based Space Vector Modulation based on common mode voltage addition and unique zero vector utilization 
PWM

\section{Comparison of Sinusoidal PWM and Space Vector}

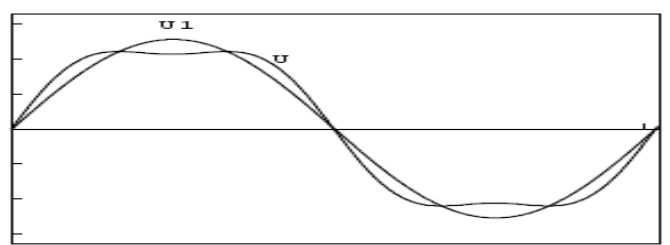

Fig. 24: Phase-to-center voltage by space vector PWM

1) In the Fig. 24 above, $\mathrm{U}$ is the phase-to-center voltage containing the triple order harmonics that are generated by space vector PWM, and U1 is the sinusoidal reference voltage. But the triplen order harmonics are not appeared in the phase-to-phase voltage as well. This leads to the higher modulation index compared to the SPWM.

2) SPWM only reaches to 78 percent of square-wave operation, but the amplitude of maximum possible voltage is 90 percent of square-wave in the case of space vector PWM. The maximum phase-tocenter voltage by sinusoidal and space vector PWM are respectively;

$\operatorname{Vmax}=V_{\mathbf{d c}} / \mathbf{2}$ : for Sinusoidal PWM; And

$V_{\max }=\mathbf{V}_{\mathbf{d c}} / \sqrt{\mathbf{3}}$, where, $\mathrm{V}_{\mathrm{dc}}$ is DC-Link voltage: for Space Vector PWM.

This means that Space Vector PWM can produce about 15 percent higher than Sinusoidal PWM in output voltage.

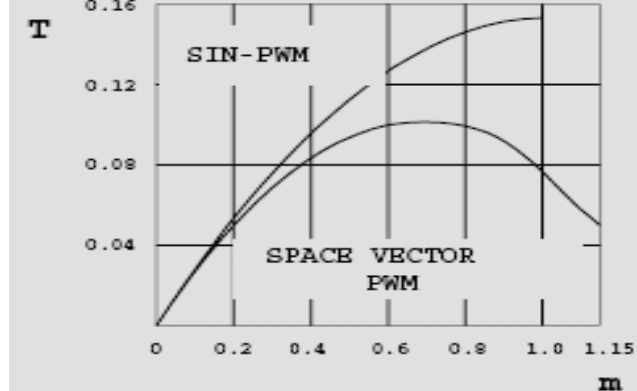

Fig. 26: torque harmonics

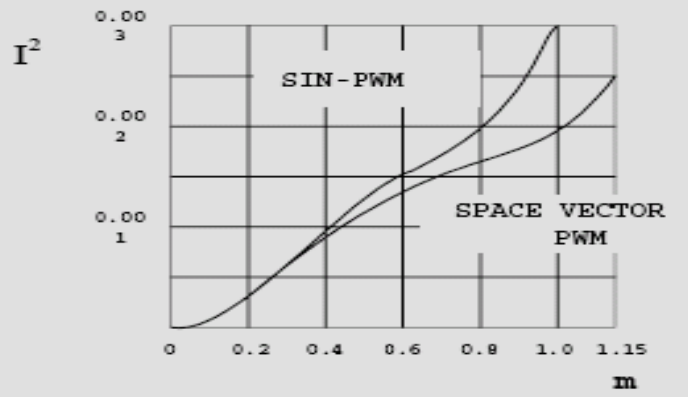

Fig. 25: Current rms harmonic

Simulation results in Fig. 25 and 26 show that the higher modulation index is, the less the harmonics of current and torque by space vector PWM are than those of sinusoidal PWM.

3) However, SVPWM algorithm used in three-level inverters is more complex because of large number of inverter switching states.

\section{Matlab Simulations}

6.1. Open Loop Speed Control of an Induction Motor using constant V/Hz Principle and SVPWM Technique

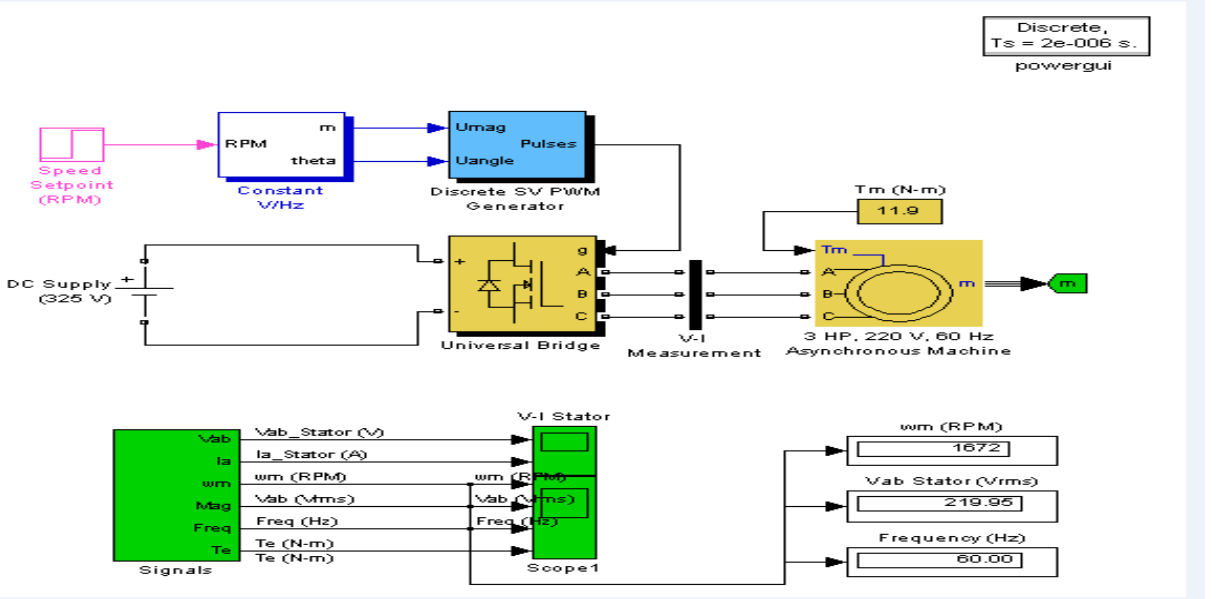

Fig. 27: Open loop speed control of an induction motor using a space vector PWM modulator 


\subsubsection{Circuit description:}

A 3-phase squirrel-cage motor rated $3 \mathrm{HP}, 220 \mathrm{~V}, 60 \mathrm{~Hz}, 1725 \mathrm{rpm}$ is fed by a 3-phase MOSFET inverter connected to a DC voltage source of $325 \mathrm{~V}$. The inverter is modeled using the "Universal Bridge" block and the motor by the "Asynchronous Machine" block. Its stator leakage inductance Lls is set to twice its actual value to simulate the effect of a smoothing

Reactor placed between the inverter and the machine. The load torque applied to the machine's Shaft is constant and set to its nominal value of 11.9 N.m. The firing pulses to the inverter are generated by the "Space-Vector PWM modulator" block of the SPS library. The chopping frequency is set to $1980 \mathrm{~Hz}$ and the input reference vector to "Magnitude-Angle".

Speed control of the motor is performed by the "Constant V/Hz" block. The magnitude and frequency of the stator voltages are set based on the speed set point. By varying the stator voltages magnitude in proportion with frequency, the stator flux is kept constant.

\subsubsection{Demonstration:}

Started the simulation. Since the initial states values have been automatically loaded, the simulation should start in steady-state. The initial motor speed should be 1720 RPM and the rms value of the stator voltages should be $220 \mathrm{~V} @ 60 \mathrm{~Hz}$.

At $0.1 \mathrm{~s}$, the speed set point is changed from 1725 to 1300 RPM. You can observe the system dynamic looking inside Scope 1. When the motor reaches a constant speed of 1275 RPM, the stator voltage rms value is down to $165.8 \mathrm{~V}$ and the frequency to $45.2 \mathrm{~Hz}$. Stator voltage (phase AB) and phase A current waveforms can be observed in the "V-I Stator" Scope. We can do a FFT of these two quantities using the power gui FFT Analysis.

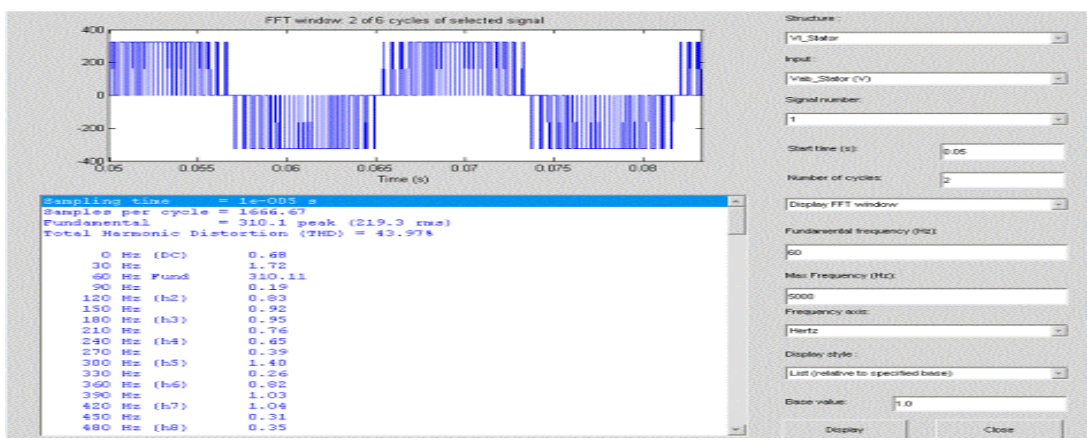

Fig. 28: FFT of stator phase voltage and current waveforms.

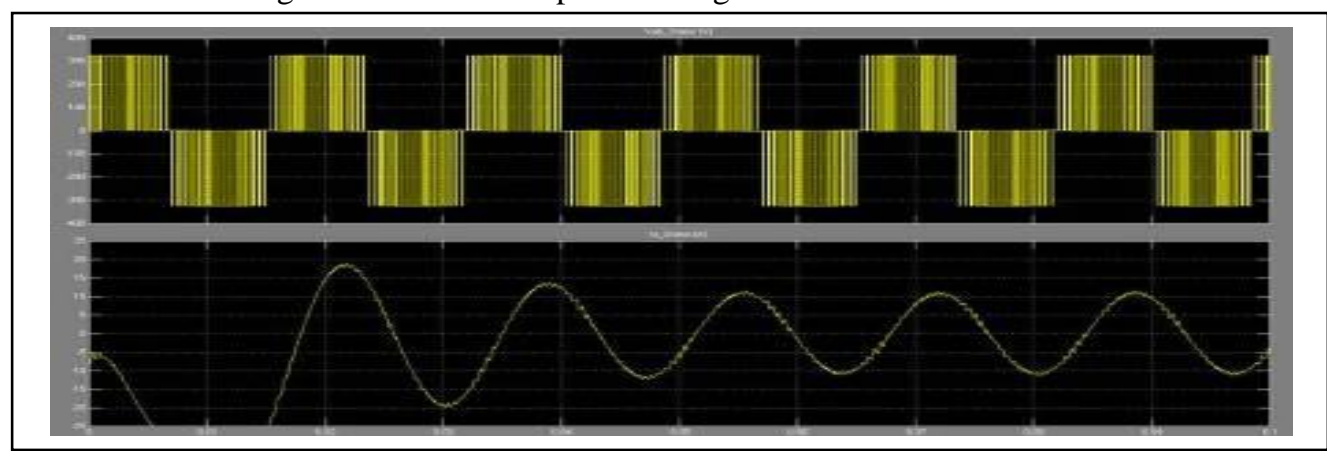

Fig. 29: Response of stator voltage $V_{a b}$ and stator current $I_{a}$ versus time

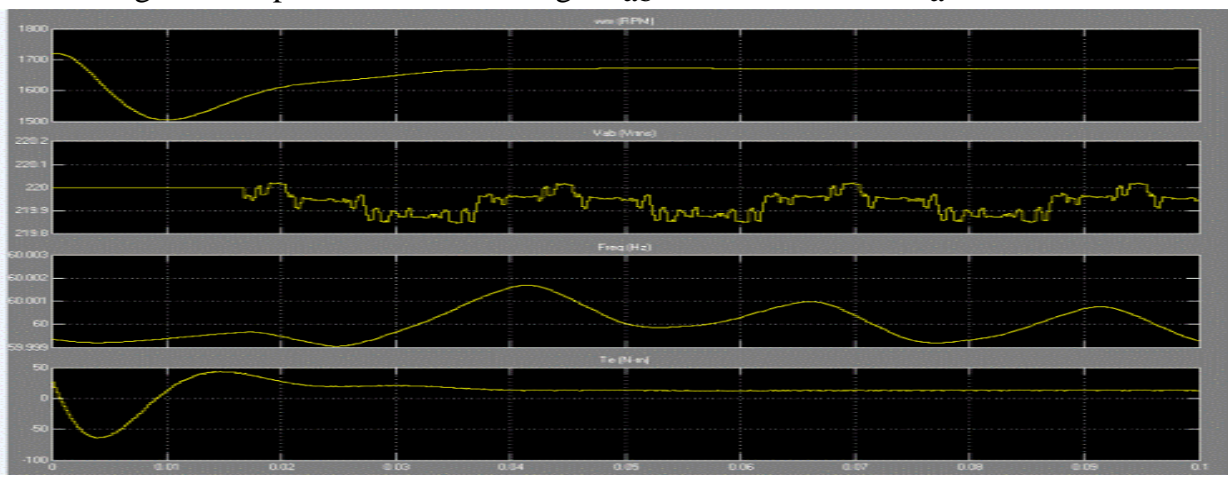

Fig. 30: Response of Speed (in rpm) of rotor, stator voltage $\left(\mathrm{V}_{\mathrm{ab}}\right)$, Freq and $\mathrm{T}_{\mathrm{e}}$ of the Induction Motor versus time 


\subsection{Model for three-phase two level PWM voltage source motors}

\section{Three-Phase Two-Level PWM Voltage Source Converters}

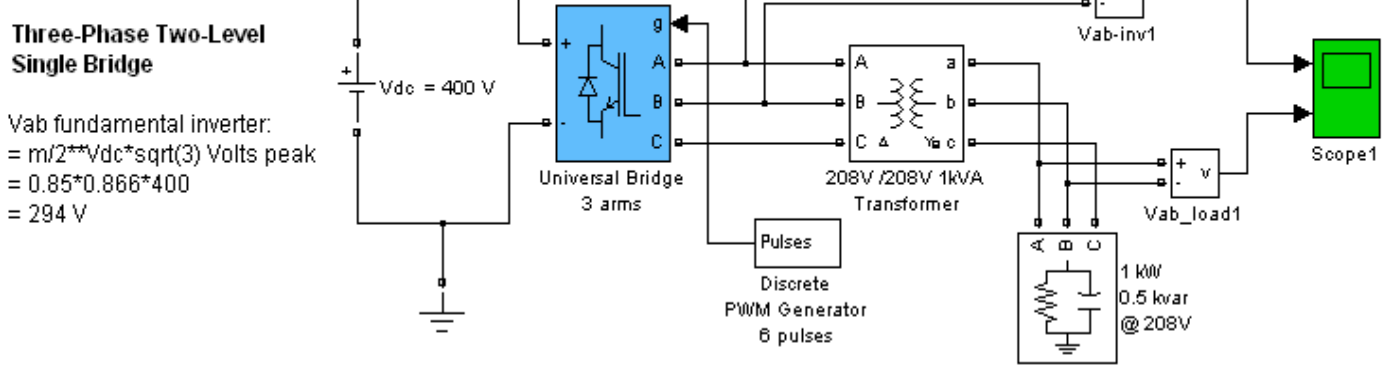

Fig. 31 Model for three-phase two level PWM voltage source motors

\subsubsection{Circuit description:}

The system consists of an independent circuit illustrating a three-phase two-level PWM voltage source inverter. The inverter feeds an AC load $(1 \mathrm{~kW}, 500$ var $60 \mathrm{~Hz} @ 208 \mathrm{~V} \mathrm{rms})$ through a three-phase transformer. It is controlled in open loop with the Discrete PWM Generator block available in the Extras/Discrete Control Blocks library. The circuit uses the DC voltage $(\mathrm{Vdc}=400 \mathrm{~V})$, carrier frequency $(1080 \mathrm{~Hz})$, modulation index $(\mathrm{m}=0.85)$ and generated frequency $(\mathrm{f}=60 \mathrm{~Hz})$. Harmonic filtering is performed by the transformer leakage inductance (8\%) and load capacitance (500 var).

\subsubsection{Simulation:}

Ran the simulation and observed the following two waveforms on the Scope block: Voltage generated by the PWM inverter (trace 1), load voltage (trace 2) Once the simulation is completed, opened the Powerful and selected 'FFT Analysis' to display the $0-5000 \mathrm{~Hz}$ frequency spectrum of signal saved.

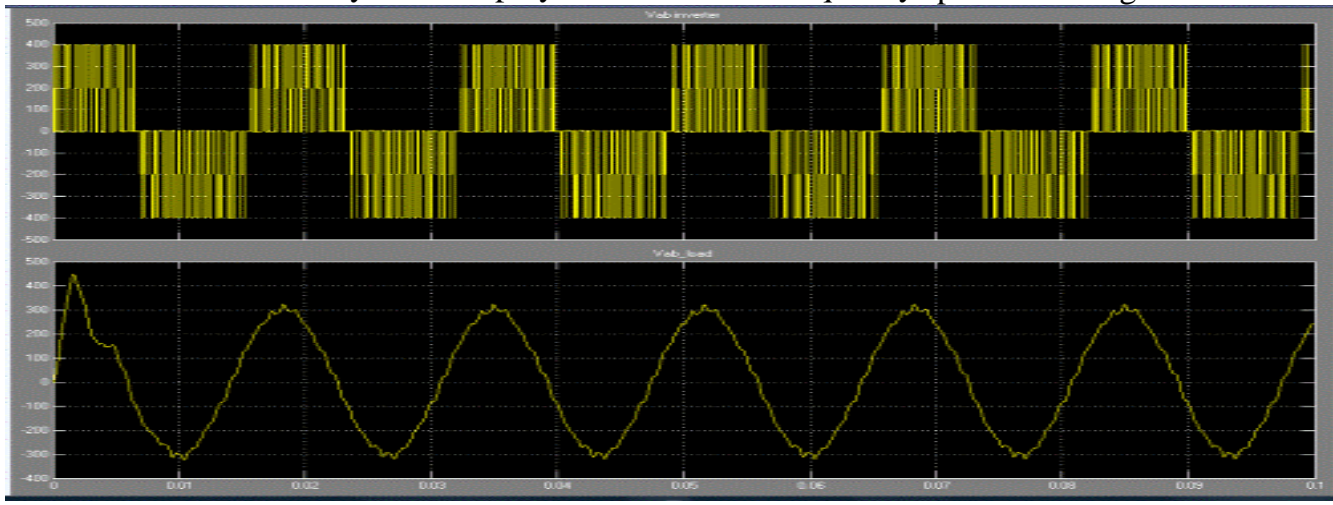

Fig. 32 Response of $\mathrm{V}_{\mathrm{ab}}$ Load and $\mathrm{V}_{\mathrm{ab}}$ Inverter versus time

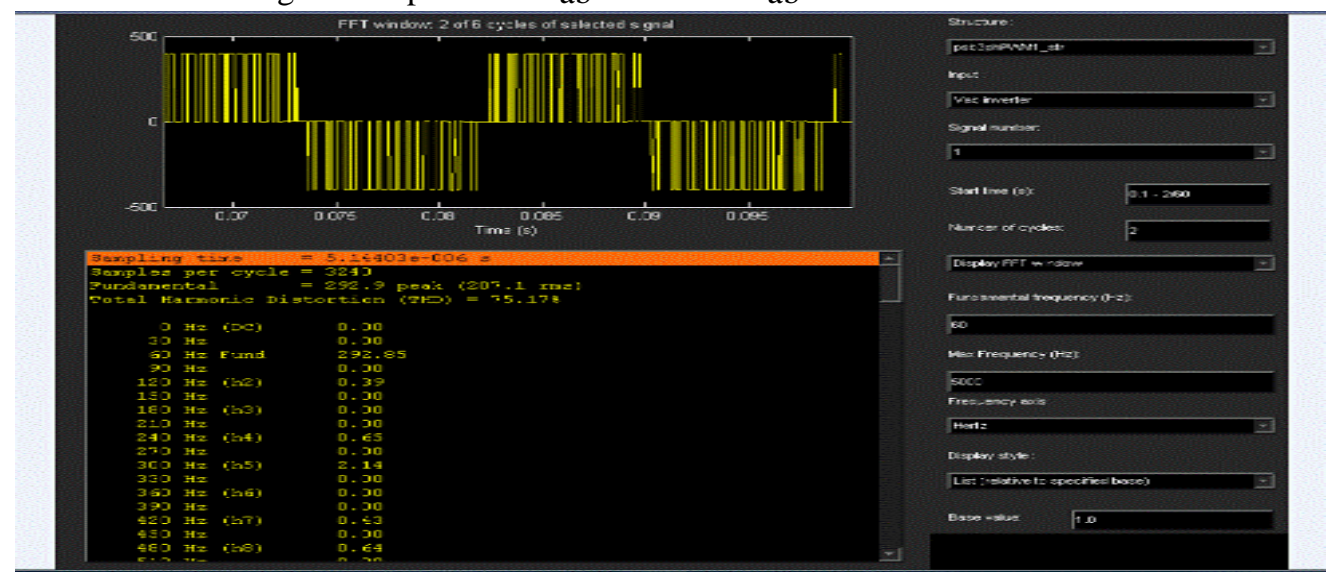

Fig. 33 'FFT Analysis' to display the 0-5000 $\mathrm{Hz}$ frequency spectrum of signal saved 


\section{Conclusion and Future work}

As seen from the above discussion Space Vector PWM is superior as compared to Sinusoidal pulse width modulation in many aspects like:

1) The Modulation Index is higher for SVPWM as compared to SPWM.

2) The output voltage is about $15 \%$ more in case of SVPWM as compared to SPWM.

3) The current and torque harmonics produced are much less in case of SVPWM.

However despite all the above mentioned advantages that SVPWM enjoys over SPWM, SVPWM algorithm used in three-level inverters is more complex because of large number of inverter switching states.

Hence we see that there is a certain trade off that exists while using SVPWM for inverters for Adjustable speed Drive Operations. Due to this we have to choose carefully as to which of the two techniques to use weighing the pros and cons of each method.

\section{References}

[1.] J. Holtz, "Pulse width modulation for electronic power conversion," Proc. IEEE, vol. 82, pp. 1194-1214, Aug. 1994.

[2.] O. Ogasawara, H. Akagi, and A. Nabel, "A novel PWM scheme of voltage source inverters based on space vector theory," in Proc. EPE European Conf. Power Electronics and Applications, 1989, pp. 1197-1202.

[3.] M. Depenbrock, "Pulsewidth control of a 3-phase inverter with nonsinusoidal phase

[4.] Voltages," in Proc. IEEE-IAS Int. Semiconductor Power Conversion Conf., Orlando, FL, 1975, pp. 389-398.

[5.] J. A. Houldsworth andD. A. Grant, "The use of harmonic distortion to increase the

[6.] Output voltage of a three-phase PWM inverter,” IEEE Trans. Ind. Applicant., vol. 20, pp. 1224-1228, Sept./Oct. 1984.

[7.] Modern Power Electronics and AC Drives, by Bimal K. Bose. Prentice Hall Publishers,2001

[8.] Power Electronics by Dr. P.S. Bimbhra. Khanna Publishers, New Delhi, 2003. 3 Edition.

[9.] A Power Electronics Handbook by M.H. Rashid. Academic Press 2001.

[10.] www.mathworks.com 